\title{
Google Street View: Walking the Line of Privacy- Intrusion upon Seclusion and Publicity Given to Private Facts in the Digital Age
}

\author{
By: Jordan E. Segall ${ }^{*}$ \\ Spring 2010 Edition- Volume X
}

Copyright (C) University of Pittsburgh School of Law Journal of Technology Law and Policy

\footnotetext{
* Jordan E. Segall is a second-year law student at The University of Pittsburgh School of Law expected to earn his J.D. in May 2011. He would like to acknowledge and thank Professor Kevin Ashley of the University of Pittsburgh School of Law for his thoughtful contributions without which this Note could not have come to fruition.
} 


\section{Introduction}

On a snowy evening, a man hears of a new restaurant opening in a distant suburb of his metropolis and looks for driving directions to take his significant other out for a romantic evening. He opens Google and conducts a driving direction search. As they have never been to the location, and as the weather is not optimal, they check the layout of the roads in order to alleviate safety concerns through Google's Street View Program. ${ }^{1}$ They click on the images next to the proposed turns and see a picture of a man walking with a woman at the intersection. Later it is disclosed in the news that this individual is a high-ranking government official and the woman is not his wife, but his mistress. ${ }^{2}$ In another image, a smoker is lounging in the background, hiding his addiction from his family and friends. ${ }^{3}$ With another click of the mouse he sees sunbathers sitting on top of the roof of a building, enjoying the warm summer day as well as the seeming privacy and anonymity of their rooftop abode. ${ }^{4}$

These photographic images associated with Google's Street View program have led to much controversy amongst governments, lawyers, and scholars around the world. Governments throughout Europe, most notably in the United Kingdom, Switzerland, and Greece, have attempted to regulate Google and the images that can be viewed through its program.

Commissions have been formed, governmental statements have been issued, and lawsuits have been initiated based on fears of Google's storage of imagery as well as the procedures to

\footnotetext{
1 http://maps.google.com/help/maps/streetview/ (last visited April 14, 2010).

2 Henry Chu, Privacy concerns delay, disrupt Google Street View in Europe, Britain, DALLAS MORNING NEWS, Sep. 14, 2009, available at http://www.dallasnews.com/sharedcontent/dws/news/world/stories/DNgoogle 14int.ART.State.Edition1.4bb965d.html.

${ }^{3}$ Andrew Lavoie, The Online Zoom Lens: Why Internet Street-Level Mapping Technologies Demand Reconsideration of the Modern-Day Tort Notion of "Public Privacy," 43 GA. L. REV 575, 577 (Winter 2009).

4 Id. at 577-78. See also Posting of Alex Turnbull to Googlesightseeing.com, http://googlesightseeing.com/2007/05/31/half-naked-sunbathing-girls-on-google-street-view (May 31, 2007) (last visited April 14, 2010).
} 
challenge and mitigate image collection. ${ }^{5}$ Moreover, recent American legal scholarship on the issue has been quite expansive in the application of the tort doctrine of privacy, ${ }^{6}$ advancing numerous rationales for the applicability of the invasion of privacy torts in the context of Google Street View. Most notably, scholars have pointed to (1) the chilling effect on behavior, hindering free speech and expression, ${ }^{7}(2)$ the lack of right to control information about oneself, ${ }^{8}$ (3) the fact that the technology used by Google is more advanced than the technology employed by ordinary cameras due to advanced magnification and centralized record collection, creating widespread dissemination through the medium of the Internet, ${ }^{9}(4)$ the lack of consent employed in imagery collection, ${ }^{10}(5)$ the lack of public benefit for Google's Street View program, ${ }^{11}$ and (6) the threat to reputation and safety Google's Street View program creates. ${ }^{12}$ As such, these concerns have led numerous scholars to call for the substantive expansion of the tort of privacy in the United States to encompass Google Street View.

In the United States, however, quite a different approach to privacy has emerged. The U.S. approach is to analyze Google Street View within the framework of the right to privacy doctrine expressed in the Restatement (Second) of Torts and by Dean Prosser, specifically in the context of intrusion upon seclusion and publicity given to private life. ${ }^{13}$ As reflected in the

\footnotetext{
5 Frank Jordans, Swiss Privacy Watchdog to Sue Google Street View, Associated PRESS, Nov. 13, 2009, available at http://abcnews.go.com/Technology/wireStory?id=9074779.

6 Lavoie, supra note 3, at 604-616; Jamuna D. Kelley, A Computer With A View, 74 BrooK. L. REV. 187, 224-30 (Fall, 2008); Josh Blackman, Omniveillance, Google, Privacy in Public, And the Right to Your Digital Identity: A Tort for Recording and Disseminating An Individual's Image Over the Internet, 49 SANTA CLARA L. REV. 313, 34192 (2009).

${ }_{8}^{7}$ Blackman, supra note 6, at 326-27, 346-47; Lavoie, supra note 3, at 604-06.

${ }^{8}$ Lavoie, supra note 3, at 606-608.

${ }^{9}$ Id. at 608-09; Kelley, supra note 6, at 196-200.

${ }^{10}$ Id. at $609-10$.

${ }^{11} I d$. at $610-12$.

12 Blackman, supra note 6, at 342-46; Posting of GagetGirl to Gaj-It.com, http://www.gaj-it.com/16550/googlestreet-view-uk-could-this-be-a-service-for-burglars/ (March 15, 2010) (last visited April 14, 2010).

${ }^{13}$ See Lavoie, supra note 3, at 583; Kelley, supra note 6, at 208-09.
} 
recent Pennsylvania case of Boring v. Google, Inc., ${ }^{14}$ which has yet to be fully analyzed at publication by American scholars and is the first U.S. case specifically regarding Google Street View, the traditional U.S. privacy approach prevents from finding that Street View is an invasion of privacy.

This Note will demonstrate that the concerns of American scholars and European governments seem to be disproportionate to the privacy dangers posed by Street View. Calls for an expanded tort of privacy to encompass the Street View program are in error. Current doctrine surrounding the tort of invasion of privacy is wholly adequate to address the advent of Google Street View due to the highly public nature of the activity in which the individuals are implicated through the program. The current system of image collection mitigation employed by Google, the backdrop of other similar tacitly accepted image capture technologies allowed in the United States and Europe, as well as the notable public benefit that the Street View program serves, all militate against a finding that Google Street View invades one's privacy in the United States.

In Section II, this Note will explain the basic technology utilized in Google Street View, including its system for image collection. It will provide a foundation of US privacy law in tort, including applicable Pennsylvania law and substantive law cited by those opposed to the current privacy framework and its application to Street View. In Section III, this Note will assess recent legal developments regarding Street View in Europe and the United States will be assessed. Finally, in Section IV this Note will analyze recent calls for an expanded tort of invasion of privacy.

${ }^{14}$ Boring v. Google, Inc., 598 F.Supp.2d 696 (W.D. Pa. 2009). 


\section{Foundations}

\section{A. The Technology of Google Street View}

Google began its first foray into Internet mapping in 2004, when it acquired Keyhole Corporation and the mapping software rights that would become the popular Google Earth program. ${ }^{15}$ Google Earth allows users to input any address or point of interest in the world and see detailed photographic images of that location. This type of technology had been widely available to government entities, but Google Earth was the first example of such technology employed by private companies for widespread distribution. ${ }^{16}$ Security concerns abounded in the United States and India about the ability of users to view in detail the White House, U.S. Capitol, and numerous military bases. Google responded with blurring numerous images from their usual high-quality detailed structure. ${ }^{17}$

Around the same time Google Earth was launched, Google released Google Maps, a service offering "powerful, user-friendly mapping technology and local business informationincluding business locations, context information, and driving directions." ${ }^{18}$ In 2007, Google debuted its Street View system, in addition to the Google Maps program, providing 360-degree snapshots of thousands of addresses. For its debut, images from the cities of New York, San Francisco, Denver, Las Vegas, and Miami were uploaded. ${ }^{19}$ The service has since been expanded to reach across the United States and around the world. These snapshots are taken from vehicles driving along main streets, each equipped with a special 360-degree camera that

\footnotetext{
${ }^{15}$ Posting of Bill Kilday to Googleblog.Blogspot.com, http://googleblog.blogspot.com/2005/06/cover-earth.html (June 28, 2005, 07:33 AM EST) (last visited April 14, 2010).

${ }^{16}$ Lavoie, supra note 3, at 600 .

${ }^{17}$ Id. at 600-01 (citing Andrew Scutro, Satellite Imagery Renews Secrecy Debate; Detailed Photos on the Internet Spark Concern, Marine Corps Times (Springfield, Va.), Sept. 3, 2007, at 28; Rich Gibson \& Schuyler Erie, Google Maps Hacks, O’Reilly Media, Inc. (Sebastopol, Ca.), 2006, at 180-82).

${ }^{18}$ Google Maps Help Center, What Is Google Maps?, http://maps.google.com/support/bin/answer.py?answer=7060 (last visited April 14, 2010).

${ }^{19}$ Lavoie, supra note 3, at 602.
} 
snaps pictures at specific intervals, along with roof-mounted devices with camera lenses, which capture images of buildings, automobiles, and even passersby. ${ }^{20}$ These cameras produce overlapping pictures that create a seamless panoramic view of a street. ${ }^{21}$ Arrow buttons let the user move in a particular direction and rotate the view of the camera 360 degrees on the street. ${ }^{22}$ Vertical viewing is also available with a zoom that allows users to pan the facades of fifty-story skyscrapers. $^{23}$ It is as if the user were standing on the street corner when the image had been taken. Image quality varies by city. In San Francisco, San Diego, Phoenix, Tucson, and parts of Chicago, images were filmed in high resolution, giving the user increased zooming ability. ${ }^{24}$

Currently Google attempts to automatically blur the images of individuals and car license plates. $^{25}$ If, however, a passerby appears on one of Street View's snapshots they may click on Street View's help button allowing them to report their captured and published image. ${ }^{26}$ Images involving nudity, sensitive locations, or clearly identifiable individuals are subject to removal, with other complaints taken under consideration. ${ }^{27}$ In order to protect domestic violence victims Google has worked to keep images of shelters private by not displaying images of the shelter or patrons. The standards for complete removal of an image, however, were initially quite stringent, particularly with respect to readily identifiable people. Initially Google requested that a user

\footnotetext{
${ }^{20}$ Posting of Mike Spinelli to Jalopnik.com, http://www.jalopnik.com/cars/maps/google-street-view-how-they-didit-265092.php (June 1, 2007, 9:00 EST) (last visited April 14, 2010).

${ }^{21}$ Elinor Mills, Google Now Zaps Faces, License Plates on Map Street View, CNET News.Com, Aug. 22, 2007 (2:02 PM PDT), http://www.news.com/8301-10784 3-9764512-7.html (last visited April 14, 2010).

22 Posting of Brady Forrest to Radar.Oreilly.com, http://radar.oreilly.com/2007/05/where-20-google-launchesstree.html (May 29, 2007) (Showing screen shot of the Street View interface and directional buttons) (last visited April 14, 2010).

${ }^{23}$ Posting of Stephane Lafon to Google-Latlong.Blogspot.com, http://google-latlong.blogspot.com/2007/10/morestreet-view-cities-to-explore.html (Oct. 9, 2007, 5:46 EST) (last visited April 14, 2010).

${ }^{24}$ See Posting of Stephen Chau to Google-Latlong.Blogspot.com, http://googlelatlong.blogspot.com/2007/05/introducing-street-view.html (May 29, 2007, 10:11 EST) (last visited April 14, 2010).

${ }^{25}$ Google Maps, Privacy, http://maps.google.com/help/maps/streetview/privacy.html (last visited April 14, 2010).

${ }^{26}$ Michael Liedtke, Google Hits the Streets, Raises Concerns, WASH. POST (June 1, 2007) available at http://www.washingtonpost.com/wp-dyn/content/article/2007/06/01/AR2007060101488.html.

${ }^{27}$ Lavoie, supra note 3, at 603 (citing Jesse Leavenworth, Street View Raises New Privacy Concerns, THE RECORD, June 25, 2007, at D2).
} 
submit his name, email address, a sworn statement, and a copy of a valid photo ID. ${ }^{28}$ Now anyone can file an online "Report of Inappropriate Street View" with a description of the problem and a valid e-mail address. Users must provide their name and the location of the image, neither of which can be used by Google for any other purpose. The image of the individual, or car license plate number, can then be blurred so as to be un-recognizable. ${ }^{29}$

\section{B. Privacy Law Foundations: Dean Prosser and the Restatement}

Privacy law is not uniform throughout the United States. It has developed on a state-bystate basis, according to each state's tort law system, with some states completely eschewing a right to privacy. ${ }^{30}$ In his seminal 1960 article, Dean Prosser outlined four distinct torts within the tort of invasion of privacy, each protecting different interests. These four interests are: (1) intrusion upon the plaintiff's seclusion, solitude, or private affairs, (2) public disclosure of embarrassing private facts about the plaintiff, (3) publicity which places the plaintiff in a false light in the public eye, and (4) appropriation, for the defendant's advantage, of the plaintiff's name or likeness. ${ }^{31}$ While varying torts for invasion of privacy exist, the most notable for purposes of evaluating the legal implications of Google Street View are intrusion upon seclusion and public disclosure of private facts.

To recover for a claim of intrusion upon seclusion, a plaintiff must show that the matter is secret or private, that they have a right to keep the information secret, and that the information

\footnotetext{
${ }^{28}$ Posting of Kevin Poulsen to Wired.com, http://www.wired.com/threatlevel/2007/06/want_off_street/ (June 15, 2007, 13:41 EST) (last visited April 14, 2010).

${ }^{29}$ Mills, supra note 21; Google Maps, Privacy, supra note 25.

${ }^{30}$ Lavoie, supra note 3, at 582 (citing HARRY HENDERSON, PRIVACY IN THE INFORMATION AGE, 40-57 (Facts on File 1999)).

${ }^{31}$ William L. Prosser, Privacy, 48 CAL. L. Rev. 383, 389 (1960).
} 
about the matter was discovered by unreasonable or highly offensive means. ${ }^{32}$ 'Intrusion' refers to physical invasion of a private place or "sensory intrusions such as visual or photographic spying."33 Moreover, the intrusion upon seclusion tort only applies when the individual was in a private location, not public property. ${ }^{34}$

The tort of public disclosure of private facts has generally been defined as reaching situations in which factual information about a matter highly offensive to someone is broadly exposed to the greater public without a concurrent public interest or newsworthiness in the information. $^{35}$ Newsworthiness is broadly defined and judges generally defer to editors to determine newsworthiness. As such, the state may only penalize publications for truthful information based upon interests of the highest order. ${ }^{36}$

Dean Prosser further limited the tort of public disclosure of private facts in stating, "On the public street, or in any other public place, the plaintiff has no right to be alone, and it is no invasion of his privacy to do no more than follow him about." ${ }^{, 37}$ Prosser maintained that such an instance was nothing more than making a record and did not differ from a full written description of a public sight, which anyone present would be able to see. ${ }^{38}$ Judges have largely agreed with Prosser's viewpoint, as demonstrated by the many cases where courts have disposed of public

\footnotetext{
32 Matthew C. Keck, Cookies, the Constitution, and the Common Law: A Framework for the Right of Privacy on the Internet, 13 ALB. L.J. SCI. \& TECH. 83, 106 (2002), (quoting Beaumont v. Brown, 237 N.W.2d 501, 505 (Mich. Ct. App. 1975)).

${ }^{33}$ Clay Calvert \& Justin Brown, Video Voyeurism, Privacy, and the Internet: Exposing Peeping Toms In Cyberspace, 18 CARDOZO ARTS \& ENT. L.J. 469, 557 (2000) (quoting Schulman v. Group W Prods. Inc., 955 P.2d 469, 489 (Cal. 1998)).

${ }^{34}$ See Gill v. Hearst Publ'g Co., 253 P.2d 441, 446 (Cal. 1953).

35 Restatement (SECOND) OF TORTS § 652D (1977), REsTATEMENT (SECOND) OF TORTS $\S 652 \mathrm{D} \mathrm{cmts.} \mathrm{b} \mathrm{and} \mathrm{d}$ (1977); Prosser, supra note 31, at 396, 398.

${ }^{36}$ See Fla. Star v. B.J.F., 491 U.S. 524, 550 (1989) (White, J., dissenting). It is to be noted that this newsworthiness requirement implicates core First Amendment values and newsworthiness is to be questioned in very limited circumstances. See discussion infra pp. 29-30.

${ }^{37}$ Prosser, supra note 31 , at 391.

${ }^{38}$ Id. at 391-92.
} 
disclosure of private facts suits prior to jury deliberation. ${ }^{39}$ The rationale behind Prosser's public display rationale has two branches. The first branch is contractual theory. Reasonable people know that entering a public space entails some degree of visibility to others; a person thus implicitly consents to being watched by others when in a public area. ${ }^{40}$ The second branch is voluntary assumption of risk. This occurs when a plaintiff voluntarily and knowingly puts himself or herself at risk for harm suffered and thus cannot recover. ${ }^{41}$ Further, Prosser reasoned that the public disclosure element of the privacy tort was meant to embrace the same elements of mental distress that are present in libel and slander. ${ }^{42}$ As such, the image itself must be highly offensive to a reasonable person. ${ }^{43}$

The Restatement (Second) of Torts has largely adopted Prosser's limitations on the publicity given to private facts tort. ${ }^{44}$ The Restatement, however, has expanded the limits slightly by adding a public concern requirement to Prosser's standard. The Restatement states,

One who gives publicity to a matter concerning the private life of another is subject to liability to the other for invasion of his privacy if the matter publicized is of a kind that

(a) would be highly offensive to a reasonable person and

(b) is not of a legitimate concern to the public. ${ }^{45}$

\footnotetext{
39 Andrew Jay McClurg, Bringing Privacy Law Out of the Closet: A Tort Theory of Liability for Intrusions in Public Places, 73 N.C. L. REV. 989, 999-1006 (1995).

40 Prosser, supra note 31, at 391-92; RESTATEMENT (SECOND) OF TORTS § 652D cmt. c (1977) ("Complete privacy does not exist in this world except in a desert, and anyone who is not a hermit must expect and endure the ordinary incidents of the community life of which he is a part.").

${ }^{41}$ David G. Owen, Products Liability: User Misconduct Defenses, 52 S.C. L. REV. 1, 24 (2000) (citing BLACK'S LAW DiCTIONARY 1569 (7th ed. 1999) ("The underlying idea of the assumption of risk defense is that a user has fully consented to incur a risk which the user fully comprehends. By the act of incurring the risk, the user thus implicitly agrees to take responsibility for any harmful consequences that may result from the encounter and so relieves the person who created the risk from responsibility."). See also, Kelley, supra note 6, at 212 (citing Prosser \& Keeton On The LaW Of Torts $§ 68$ (W. Page Keeton et. al. eds., West Pub. Co., 5th ed., 1984)).

42 Prosser, supra note 31, at 398.

${ }^{43}$ Keck, supra note 32, at 106.

${ }^{44}$ Restatement (SECOND) OF TORTS, § 652D (1977). See, e.g., Marc Jonathan Blitz, Video Surveillance and the Constitution of Public Space: Fitting the Fourth Amendment to a World that Tracks Image and Identity, 82 TEX. L. REV. 1349, 1379 n.162 (2004) (listing illustrative cases).

45 RestatemEnt (SECOND) OF TORTS, § 652D (1977).
} 
The Restatement comments also adopt Dean Prosser's mental distress requirement for the publicity given to private facts tort, stating,

Every individual has some phases of his life and his activities and some facts about himself that he does not expose to the public eye, but keeps entirely to himself or at most reveals only to his family or to close personal friends. . . . When those intimate details of his life are spread before the public gaze in a manner highly offensive to the ordinary reasonable man there is an actionable invasion of his privacy unless the matter is one of legitimate public interest. ${ }^{46}$

Thus Dean Prosser and the Restatement (Second) of Torts have clearly demonstrated the quite limited applicability of the tort claims of intrusion upon seclusion and publicity given to private facts. This limited applicability would extend to the photographs captured on Google Street View since the behavior is out in the open in a public place, the usage serves a noteworthy public benefit, and the mental distress suffered by individuals does not often rise to the level of shame and mental humiliation. ${ }^{47}$

States' acceptance of the Restatement and Prosser's privacy torts, however, was not universal. Half of the fifty states have accepted all four of the privacy torts; several others have declined to adopt the tort of false light. ${ }^{48}$ Moreover, even in the States that claim to accept all four privacy torts, plaintiffs often fail to recover due to widespread "judicial wariness" of the privacy torts. ${ }^{49}$ Pennsylvania, however, has explicitly adopted the requirements of Dean Prosser and the Restatement in stating that, under the publicity given to private facts tort, publicity must be given to private facts that would be highly offensive to a reasonable person for an illegitimate

\footnotetext{
46 RESTATEMENT (SECOND) OF TORTS $\S 652 \mathrm{D} \mathrm{cmt}$. b (1977).

47 See discussion infra pp. 24-25, 29 of Street View's public service as well as discussion infra pp. 20-22 of mental humiliation in the context of the Boring decision.

48 McClurg, supra note 39, at 998-99.

49 Id. at 999-1007.
} 
public-concern. $^{50}$ Regarding intrusion upon seclusion, a physical intrusion is required into a place where the plaintiff has secluded himself through the use of the defendant's senses to oversee or overhear the plaintiff's private affairs. An alternative requirement is that some other form of intrusive investigation into the plaintiff's private affairs must be undertaken. The plaintiff also must prove that the intrusion was substantial and would be highly offensive to an ordinary reasonable person, as well as would be expected to cause mental suffering, shame, or humiliation to a person of ordinary sensibilities. ${ }^{51}$

\section{Privacy Law- Jurisprudence}

Much of the jurisprudence cited by American scholars in their calls for an expansive tort of privacy in regards to Google Street View has been based on Supreme Court case law. ${ }^{52}$ This case law, however, deals with criminal proceedings or disclosure of information about crime victims, and is outside of the purview of Street View. ${ }^{53}$

A case far more analogous to Street View situations is Gill v. Hearst Publishing Co. $^{54}$ In Gill, a couple was seated on a park bench, a photo was taken, and subsequently the photo was published in a magazine. The couple sued based on invasion of privacy grounds. The Court upheld the photo publication because the act of the couple's sitting on a park bench was voluntarily assumed in a public place. ${ }^{55}$ The court held that if an event is newsworthy, there must be a balancing test between the right to be let alone and the "the public interest in the dissemination of news and information consistent with the democratic processes under ...

\footnotetext{
50 Privacy and Publicity- Depiction of plaintiff's property on Google Map's Street View did not constitute an actionable invasion of privacy, 21 BUS. TORTS REP. 183, 184 (2009).

${ }^{51} \mathrm{Id}$. at 184.

52 See, e.g., Lavoie, supra note 3, at 587-91 (discussing Cox Broad. v. Cohn, 420 U.S. 469 (1975) and Fla. Star v. B.J.F., 491 U.S. 524 (1989)).

53 See, e.g., Cox Broad. v. Cohn, 420 U.S. 469 (1975); Fla. Star v. B.J.F., 491 U.S. 524 (1989).

54 Gill v. Hearst Publishing Co., 253 P.2d 441 (Cal. 1953).

${ }^{55}$ Id. at 444.
} 
freedom of speech and of the press." ${ }^{, 56}$ The key to this balancing test is the definition of newsworthiness, to be determined by editors and the prevailing publication and societal standards of the time. ${ }^{57}$ The photo "permitted other members of public not at the place of photo at time of taking to see individuals as they had voluntarily exhibited themselves." ${ }^{.58}$ The consequences of holding that this kind of publication is illegal, according to the Court, would be that "no periodical could lawfully publish a photo of a parade or a street scene." $" 59$ The photo merely portrayed an incident that may be seen almost daily in ordinary life. ${ }^{60}$

In a vigorous dissent, Justice Carter claimed that the photo had no legitimate public purpose or interest as well as no news or educational value. ${ }^{61}$ Noting that the identity of the couple was not necessary to advance any journalistic aspects of the story, Justice Carter commented "there is no reason why the publisher need invade the privacy of John and Jane Doe for his purpose. ${ }^{, 62}$ The plaintiffs were not intentionally placing themselves on public display by attending a major event, but were instead sharing an intimate moment when their photograph was taken. ${ }^{63}$ Justice Carter drew a distinction between what is viewable in public and viewable by reproduction. What the couple "did in view of a tiny fraction of the public, does not mean that they consented to observation by the millions of readers of the defendant's magazine., ${ }^{64}$

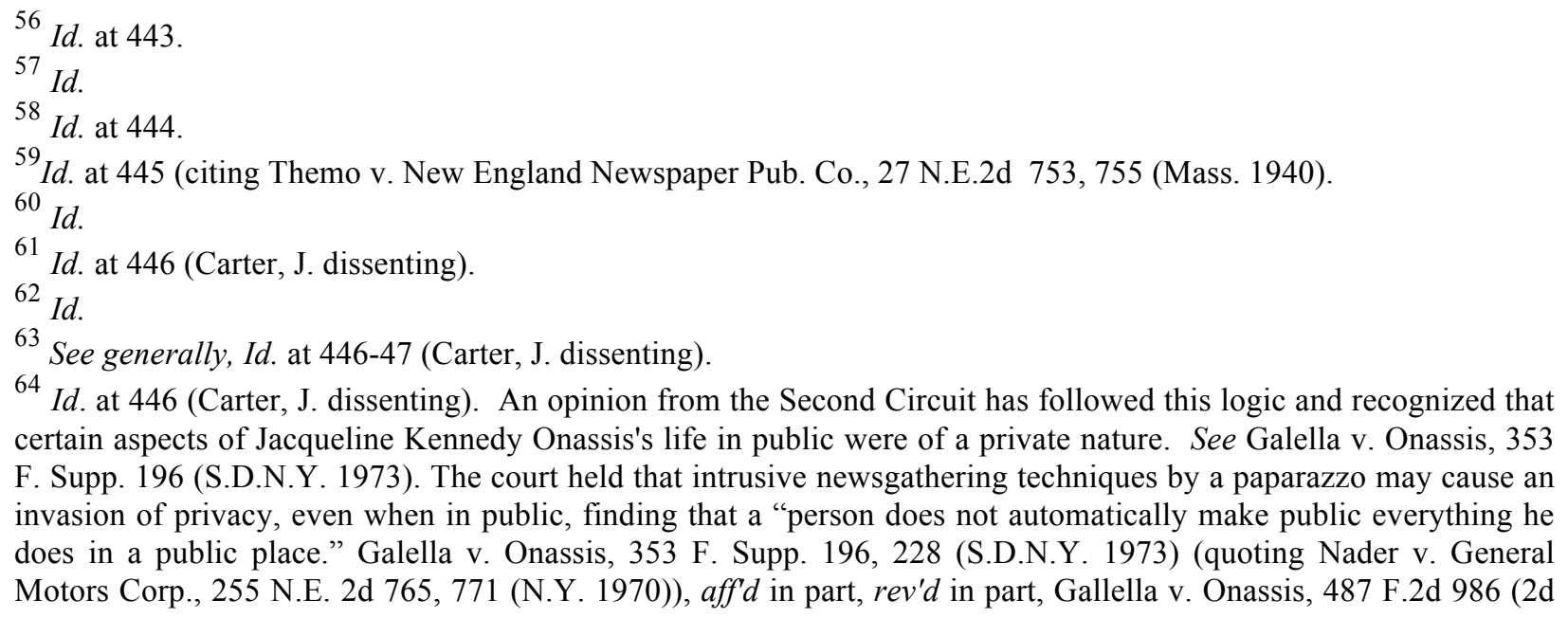
certain aspects of Jacqueline Kennedy Onassis's life in public were of a private nature. See Galella v. Onassis, 353 F. Supp. 196 (S.D.N.Y. 1973). The court held that intrusive newsgathering techniques by a paparazzo may cause an invasion of privacy, even when in public, finding that a "person does not automatically make public everything he does in a public place." Galella v. Onassis, 353 F. Supp. 196, 228 (S.D.N.Y. 1973) (quoting Nader v. General Motors Corp., 255 N.E. 2d 765, 771 (N.Y. 1970)), aff'd in part, rev'd in part, Gallella v. Onassis, 487 F.2d 986 (2d 
This distinction has become a central theme of proponents of an expanded privacy tort for the Street View program and is to be addressed infra in Section IV.

Applying the majority position in Gill, Google Street View plaintiffs would be without remedy. Images of the smoker on the street ${ }^{65}$ are merely images of an individual voluntarily in a public setting at a moment in time. Moreover, like the couple in Gill, the individuals in the Google Street View program are taking part in activity that is part of normal daily life. Just as the casual magazine reader could more than likely not view the Gill couple at the specific moment in time of image capture, the casual Street View browser could more than likely not view the public display of the smoker at the time of Google's image capture. ${ }^{66}$

In Florida Star v. B.J.F., ${ }^{67}$ the U.S. Supreme Court dealt with a criminal proceeding, outside of Street View's purview. Yet the Supreme Court precedent is also applicable as foundational law for the infant Google Street View issue due to its discussion of photographs and information gleaned from public sources. In Florida Star, the Justices extended their ruling in Cox Broadcasting v. Cohn ${ }^{68}$ and held that a rape victim could not collect damages from a newspaper for publishing her name without her consent because the information was truthful and obtained from publicly held documents. ${ }^{69}$ Truthfulness and the extent to which information is

Cir. 1973) (The District Court's invasion of privacy grounds were affirmed on appeal, the injunction imposed was modified as being an overbroad remedy).

${ }^{65}$ See discussion supra p. 1.

${ }^{66}$ See discussion infra pp. 28-30 for analysis of Justice Carter's dissent and the newsworthiness/public interest issue from Gill.

${ }^{67}$ Fla. Star v. B.J.F., 491 U.S. 524 (1989).

${ }^{68}$ Cox Broadcasting v. Cohn, 420 U.S. 469 (1975). This case is far more focused on the historic role of the press and the specific nature of judicial proceedings. In Cox, the Justices held that a father's cause of action under public disclosure of private facts was invalid when his deceased daughter's name was discovered in judicial records and released publicly on a television news report as a rape victim. The Court held that there is a zone of privacy around every individual, which may be protected from the press. The Justices, however, also maintained that since the record was discovered through the judicial process, whose accurate reporting must be preserved, and given the historic role of the press in reporting criminal proceedings, the placement of the information in the public domain of court records is presumed to serve the State's public interest.

${ }^{69}$ Fla. Star, supra note 67, at 541. 
publicly available, or ease of location, affect the private nature of the disclosed information. ${ }^{70}$ The Court declined to hold that just because something was true means it is always protected. Therefore, the easier accessed and more public the information, the less likely the tort of public disclosure of private facts is to be successful. Furthermore, when the form of disclosure takes the form of a photograph (which did not occur in Florida Star), a plaintiff's identity must be revealed by the image in order for them to recover. ${ }^{71}$ Justices Rehnquist, White, and O'Connor dissented from the Florida Star holding. These Justices held that the Court's reasoning was too protective of the press and that clear fairly defined areas of privacy were essential to maintain a reasonably acceptable quality of life. ${ }^{72}$

Florida Star directly affects a plaintiff suing Street View with a claim of public disclosure for private facts because the photograph offered by the plaintiff is detrimental to his cause of action. The image is of a public space and Google can successfully argue that the image's contents are not private to begin with because they were on public display. ${ }^{73}$ Google employed this argument in the Boring case discussed infra, and this defense was successfully established in Jackson v. Playboy Enterprises. ${ }^{74}$ In Jackson, three men who were lost asked a policewoman on the street for directions and were photographed while speaking with her. ${ }^{75}$ The policewoman later appeared as a model in Playboy magazine, and the photograph of her speaking to the boys appeared with her nude pictorial. ${ }^{76}$ The court dismissed the plaintiffs' claims under all four privacy torts because the photo was taken on a public sidewalk in plain

\footnotetext{
${ }^{70}$ Keck, supra note 32, at 107 (quoting U.S. Dep't of Justice v. Reports Comm., 489 U.S. 749,764 (1989)).

71 Calvert \& Brown, supra note 33, at 564.

${ }^{72}$ Fla. Star, supra note 67, at 547 n.2, 551-52 (citing Virgil v. Time, Inc., 527 F.2d 1122, 1128 (9 ${ }^{\text {th }}$ Cir. 1975)).

73 It could be maintained that Street View is dissimilar from Florida Star because Google privately holds the photographs. This, however, does not mitigate the fact that the images are public to begin with and truthfulness can be more easily verified. See discussion infra p. 14 of Florida Star and Jackson.

${ }^{74}$ Kelly Jackson v. Playboy Enterprises, Inc., 574 F. Supp. 10 (S.D. Ohio 1983).

75 Id. at 11 .

${ }^{76} \mathrm{Id}$.
} 
view of the public eye. ${ }^{77}$ Additionally, on the issue of Playboy's production of the photo without the men's consent, the court held that "there is no liability when the defendant merely gives further publicity to information about the plaintiff that is already public., ${ }^{, 78}$

Combining the Florida Star and Jackson precedents is fatal to the Google Street View plaintiff. The images challenged on Google Street View do not identify the individuals photographed and are already in plain view of the public eye since they are taken on public streets. The image is thus not private at the outset. Moreover, the information gleaned is truthful in nature. The smoker is in fact smoking a cigarette. Photographic evidence has verified the truthfulness of such assertions. This reality is confirmed because the Street View program inherently has greater mechanisms of verification than the publication in Florida Star. There is a greater ease of public access with the Street View program, as opposed to public court documents, since it is on the Internet and all of the images collected are on the public streets, an even more open public forum than the courtroom.

\section{Google Street View- Recent Developments}

\section{A. Europe}

The European Union has quite stringent privacy protections. The British Commonwealth also has high standards of privacy protection due to stricter and more uniform regulation of private enterprise. While the British centralization of government and weaker constitutional protections of free speech and the press make it harder to object to privacy abuses, the idea of

\footnotetext{
77 Id. at $13-14$.

78 Id. at 13 quoting RESTATEMENT (SECOND) OF TORTS $\S 652 \mathrm{D} \mathrm{cmt.} \mathrm{b} \mathrm{(1977).} \mathrm{In} \mathrm{both} \mathrm{this} \mathrm{case} \mathrm{and} \mathrm{Gill} \mathrm{consent}$ was not necessary for the magazine to reproduce the photograph as it is not an element or defense to the cause of action for publicity given to private facts, but the privacy tort of false light. See C. Katherine Mann, Invasion of Privacy by False Light Publicity, 6 Am. Jur. Proof of Facts 3d 585, at $\S 22$ (Originally published in 1989).
} 
safeguarding one's choice to disclose private information is still a key strand of British thought. ${ }^{79}$

Article 6 of the Directive on Data Protection promulgated in the European Parliament and Council of October 24, 1995, maintains that member states' personal data collection must be "for specified, explicit, and legitimate purposes; not further processed in a way incompatible with those purposes." ${ }^{80}$ Appropriate safeguards must be implemented and collection must be accurate, adequate, relevant, and not excessive in relation to the purposes for which the information is collected. Inaccurate information must be rectified through "every reasonable step," having regard for the purposes for which the information was collected. These reasonable steps include erasure and the keeping of the information "in a form which permits identification of data subjects for no longer than is necessary for the purposes for which the data were collected." $" 81$

In regards to the gathering and processing of personal data, as per Article 7 of the European Parliament's Directive on Data Protection, consent must be given unambiguously. Without consent, the party must be: a party to a contract in which the data is subject, necessary for the compliance with a legal obligation, necessary to protect the vital interests of the data subject, necessary for the performance of a task carried out in the public interest or through the official authority vested in the third party, or the processing must be necessary for the legitimate interests pursued by the third party. ${ }^{82}$ When information is collected about an individual the

\footnotetext{
${ }^{79}$ Henderson, supra note 30, at 60; See generally, Bridget Treacy, Bridget Treacy considers privacy beyond the lazy, hazy days of summer, 9 PRIVACY AND DATA PROTECTION, Sept. 1, 2009, at 2. It is to be noted that Europe's strong tradition of privacy can be seen as a response to the experiences of World War II and the Cold War in which government collection of personal information was rampant and used as a means to regulate individual behavior. See, e.g., Scott Rempell, Privacy, Personal Data and Subject Access Rights in the European Data Directive and Implementing UK Statute: Durant v. Financial Services Authority As a Paradigm of Data Protection Nuances and Emerging Dilemmas, 18 Fla. J. INT'L L. 807, 813-14 (December 2006) (citing Fred H. CATE, PRIVACY In THE INFORMATION AGE 43-44 (1997)).

${ }^{80}$ Henderson, supra note 30 , at 57.

${ }^{81} \mathrm{Id}$. at 57-58.

${ }^{82}$ Id. at 58 .
} 
following information must be provided, as per Article 10 of the European Parliament's

Directive on Data Protection: the identity of the third party with the information, the purposes of the processing, and any further information such as the recipients of the data, the existence of a right of access, and the right to rectify the data. ${ }^{83}$

Finally, the EU has provisions regarding the sharing of personal information with other nation states. In Article 25 of the European Parliament's Directive on Data Protection, it is maintained that personal data is not to be shared with countries that do not have similarly strict protections in place. "Doing so could lead to improper disclosure or other abuses and ultimately defeat the purpose of the legislation." ${ }^{\prime 44}$ Similar provisions shall be evaluated based upon: the circumstances surrounding the data transfer, the nature of the data, the purpose and duration of the proposed processing, the country of origin and final destination, the rules of law in force in the third country, and the professional rules and security measures complied with in the third country. ${ }^{85}$

In accord with this tradition of privacy protection, angst has formed in Europe regarding Google Street View. In February, 2010, the head of the EU Data Protection Agency, Alex Turk, informed Google that it must give advanced notice of where it intends to photograph on Google's website and local media. This request has been complied with as Google recently has posted alerts on its website of photographing in Italy and France. Moreover, Google has also been instructed to reduce the amount of time it retains uncensored photographs and avoid taking photographs outside of those that could be discerned by a casual passerby. ${ }^{86}$

In May 2009, the Data Protection Authority in Greece blocked Google from capturing

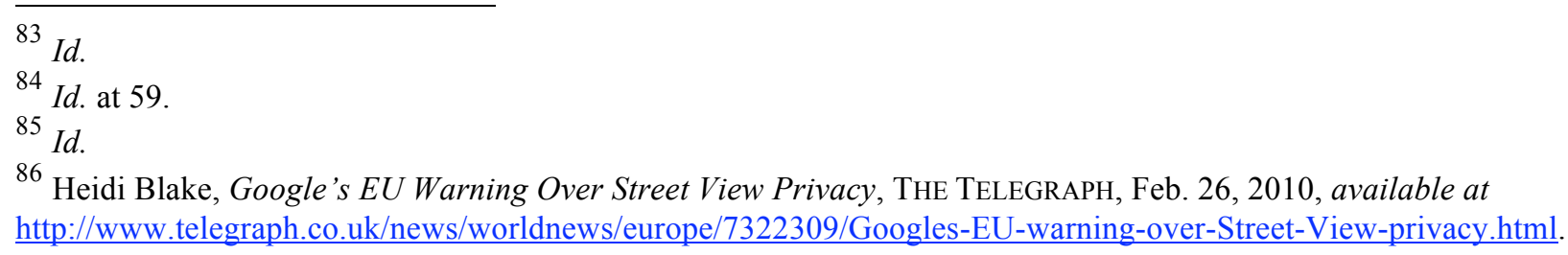


images in the country until it clarified its measures to protect privacy, including how long it stores images ${ }^{87}$ In July 2009, Greek officials rejected a bid to photograph the nation's streets until more privacy safeguards are provided. ${ }^{88}$ In the United Kingdom, the Information Commissioner's Office and other privacy rights groups, raised concerns with the program to such an extent that the Commissioner's Office launched an inquiry to determine whether the program violated the Information Protection Act of $2008{ }^{89}$

Street View was eventually approved when Google agreed to blur faces and sensitive information such as license plates as well as allow for a take-down mechanism for sensitive images. ${ }^{90}$ David Evans, Senior Data Protection Practice Manager for the UK's Information Commission, likened the images on Street View to those of people walking past reporters on television without their consent, which is perfectly legal. Evans also said that it is not in the public interest to turn the digital clock back. "In a world where many people endorse technological mediums such as . . . blogging . . . it is important to take a common sense

\footnotetext{
87 Jane E. Kirtley, Privacy Protection, Safety and Security, 987 PLI/Pat 15, at 63 (2009) (citing Derek Gatopoulos, Associated Press writer, Google's Street View Halted in Greece Over Privacy, Associated Press Financial Wire, May 13, 2009).

88 Jordans, supra note 5.

${ }^{89}$ Kirtley, supra note 86 , at 63.

90 See Warwick Ashford, Computer Weekly, Nov. 10, 2009, load date Nov. 9, 2009; Warwick Ashford, COMPUTER WeEKLy, Nov. 10, 2009, load date Nov. 18, 2009. It is to be noted that since approval Google has loaded far more high-resolution images of the UK. Google maintains this will make the face and number blurring more accurate when employed with UK images. All pre-existing takedown requests will be honored and Google plans to implement more mobile image capturing units to capture within pedestrian malls, parks, and sports venues. (See Warwick Ashford, COMPUTER WeEkly, Nov. 10, 2009, load date Nov. 9, 2009; Warwick Ashford, ComPUTER WeEkLY, Nov. 10, 2009, load date Nov. 18, 2009.). On March 12, 2010, Google officially uploaded 95\% of the United Kingdom onto its Street View Service, effectively mapping the entire nation. This mapping, however, included key military installations, with 'do not photograph' signs, prompting fears of terrorist use of the photographs and Google's removal of the military images. See Andrew Hough, Google Street View 'forced to remove images of secret British security bases', THE DAILY TELEGRAPH, March, 21, 2010, available at http://www.telegraph.co.uk/technology/google/7493217/Google-Street-View-forced-to-remove-images-of-secretBritish-security-bases.html.
} 
approach towards Street View and the limited privacy intrusion it may cause."91

Yet in Ireland, the Data Protection Commissioner voiced concerns, prior to Street View's September launch in the nation, regarding retention of Street View imagery and that it be held for "a reasonable period of time." 92 In Germany, Street View was implemented but only after undisclosed threats of German sanctions were appeased through the implementation of the ability of users to ask for the taking down of images prior to upload. This forces Google to erase the raw footage of faces, house numbers, license plates, and individuals who have told authorities they do not want their information used in the service. ${ }^{93}$

Most outspoken in its criticism of Street View, however, has been Switzerland. The head of the Swiss Data Protection Agency (DPA) found that Google's blurring technology was inadequate across Switzerland. Numerous faces and vehicle registration plates were either not wiped out or inadequately blurred, especially where the persons concerned were shown in sensitive locations, such as outside hospitals, prisons or schools. ${ }^{94}$ The DPA also took umbrage with Google's failure to inform the government where it intended to photograph more than a week in advance and failure to remove pictures of enclosed areas such as walled gardens and private streets. "The height from which the camera on top of the Google vehicle films was also problematic, providing a view over fences, hedges and walls, with the result that people see more on Street View than can been seen by a normal passer-by in the street." 96

\footnotetext{
91 Press Release, Information Commissioner's Office, Common Sense on Street View Must Prevail, Says the ICO, April 23, 2009, available at http://www.ico.gov.uk/upload/documents/pressreleases/2009/google_streetview_220409_v2.pdf.

92 See generally, Bridget Treacy, News \& Views from Around the World Ireland, 9 PRIVACY AND DATA PROT., Aug. 1,2009 , at 20.

93 See generally, Bridget Treacy, News \& Views, 9 PRIVACY AND DATA Prot., June 1, 2009, at 17.

94 Jordans, supra note 5.

95 See generally, The Month- Global Snapshots, SECURE COMPUTING MAGAZINE, Jan. 11, 2010, at 9; Jordans, supra note 5 .

96 Jordans, supra note 5.
} 
As such, the DPA called for Street View's suspension in Switzerland until Google placed concrete proposals forward for the correction of errors. ${ }^{97}$ Negotiations were attempted but failed and the Swiss government initiated a lawsuit in November 2009 in federal court attempting to force the DPA's Street View proposals. ${ }^{98}$ Google has responded that Street View is legal and is attempting to implement new technology to allow for greater blurring of images, "as fast as possible." 99 The DPA has asked the tribunal to require Google to remove all pictures taken in Switzerland and to cease taking any more pictures in the country until a ruling is made. ${ }^{100}$

In all of these instances, Google has implemented some form of safeguarding provisions similar to those in the United States to attempt automatic blurring of faces and license plates, giving advanced notice of image capture, and allowing for a take-down mechanism for collected images. Google has even pledged to work with the 29 Working Party, representing 27 European nations, in promoting even more stringent privacy protections, such as those advocated by Switzerland. ${ }^{101}$ Peter Fleischer, Google's Global Privacy Counsel, maintains that these advanced protections include providing advance public notice about when and where Google will be capturing images and taking steps to avoid holding onto the un-blurred original images any longer than needed. The technology is also being perfected to avoid false positives, or blurring portions of images that pose no privacy threat. ${ }^{102}$

\footnotetext{
97 See generally, Bridget Treacy, News \& Views, 9 PrivaCY \& DATA Prot., Sept. 1, 2009, at 17.

98 Jordans, supra note 5.

${ }^{99} \mathrm{Id}$.

${ }^{100}$ It is to be noted that Switzerland has a particularly strong tradition of privacy protection in Europe as reflected in stringent banking secrecy laws and skepticism over government use of private information. See Id.

${ }^{101}$ Kirtley, supra note 87, at 63.

${ }^{102}$ Posting of Peter Fleischer to Googlepolicyeurope.Blogspot.com, http://googlepolicyeurope.blogspot.com/2009/06/street-view-exploring-european-streets.html (June 12, 2009, 12:46 EST) (last visited April 14, 2010).
} 


\section{B. United States}

Until February 17, 2009, there was no U.S. litigation regarding Google Street View. On that date, however, the Western District of Pennsylvania ruled in the case of Boring $v$. Google. ${ }^{103}$ In Boring, the plaintiffs, who lived on a private road, discovered that images of their residence, outbuilding, and swimming pool, taken from a Google Street View vehicle in their driveway without their consent, were included in the program. ${ }^{104}$ The plaintiffs maintained that the road on which their home is located is unpaved and clearly marked with "private road" and "no trespassing" signs. As such, they claimed Google violated their right to privacy when it took pictures from their driveway at a point past the signs and when it made those photos available to the public. ${ }^{105}$ In response, Google filed a motion to dismiss the complaint.

The court dismissed the complaint and cited Pennsylvania's privacy framework, which borrows from Dean Prosser and the Restatement's tests, for intrusion upon seclusion and publicity given to private life. ${ }^{106}$ Rejecting both of plaintiffs' claims, the court maintained that Google's imagery did not meet the highly offensive requirements of either tort. Regarding intrusion upon seclusion the court held, "[i]t is hard to believe that any other than the most exquisitely sensitive would suffer shame or humiliation, ${ }^{107}$ with the plaintiff failing to assert facts proving otherwise. While others may have similar reactions of substantial offense to the images, as per plaintiffs' assertions, the court held that they failed to "set out facts to substantiate this claim," through any extrinsic evidence. ${ }^{108}$ The lack of shame or highly offensive manner of

\footnotetext{
103 Boring, supra note 14.

${ }^{104}$ Privacy and Publicity, supra note 50, at 183.

${ }^{105}$ Id.

${ }^{106}$ Boring, supra note 14, at 699-700. See discussion supra pp. 8-10.

${ }^{107}$ Id. at 700.

${ }^{108}$ Id. Here the Court can be seen to acknowledge that the norms of the community are paramount above the norms of individuals themselves. This idea is an essential crux of the torts of intrusion upon seclusion and publicity given
} 
publication was further established, according to the court, in the plaintiffs' continued attention drawn to themselves through failure to do any of the following: take advantage of the procedures Google has to remove photographic imagery, prevent others from accessing the images by eliminating their address from the pleadings, or file the action under seal. Merely "Googling" the name of the plaintiffs' attorney allowed for the dissemination of the plaintiffs' names and location as well as resulted in re-publication of the Street View images. ${ }^{109}$ "The plaintiffs' failure to take readily available steps to protect their own privacy and mitigate their alleged pain suggested that the intrusion and their suffering were less severe than asserted." 110

Similar logic was cited with the publicity given to private facts claim. The court found that the plaintiffs did not prove that the photographs revealed private facts of a type that would highly offend a reasonable person, as they failed to allege a unique or unusual situation. The court also cited the failures of mitigation of the intrusion upon seclusion claim outside litigation ${ }^{111}$ and held that the views of the property did not constitute private information. The images were available to the public by means of tax records and maps compiled by other Internet search engines. "Aside from some additional detail, the plaintiffs did not specify what information in the Google images could not be obtained or was more outrageous than information included in the public records or on other Internet sites." 112

According to the court, even if this additional information had been disclosed on Street View for the first time, it does not satisfy the Pennsylvania or Restatement (Second)'s definition of private facts. These private facts have been disclosed "when the publicity ceases to be the

to private facts. See Kelley, supra note 6, at 212; Robert C. Post, The Social Foundations of Privacy: Community and Self in the Common Law Tort, 77 CAL. L. REV. 957, 961 and 963-64 (1989).

${ }^{109}$ Boring, supra note 14 , at 700 .

110 Id.

111 The Court noted that the viability of Google Street View has not been compromised by requests that images be removed and courts have not been the appropriate forum for privacy claims based upon virtual mapping. See Id.

${ }^{112}$ Id. at 700 n.1. 
giving of information to which the public is entitled, and becomes a morbid and sensational prying into private lives for its own sake, with which a reasonable member of the public, with decent standards, would say that he had no concern." supporting the contention that Google had transgressed standards of decency, or published information that was of no public concern. ${ }^{114}$

Thus the Boring decision has steadfastly embraced the plain language and logic of the intrusion upon seclusion and publicity given to private facts claims outlined by Dean Prosser and the Restatement (Second) of Torts in regards to Google Street View. This standard has been explicitly adopted by the State of Pennsylvania. As Dean Prosser has stated, individuals on the street are in the public eye and thus have limited privacy rights. ${ }^{115}$ Boring stands for the proposition that this logic encompasses Google Street View plaintiffs even when the conduct captured is not directly on a public street, but within a more secluded location connected to public streets. Yet despite this broad ruling, the fact that the Boring decision involved a private marked roadway is essential. The traditional Street View plaintiff has been captured on a public street in which they appear in the background, similar to the smoker and government official described above, not in a secluded location. It is this traditional Street View context to which European lawmakers and American scholars have taken umbrage that is to be argued below, not the broader Boring context.

\footnotetext{
113 Id. (citing RESTATEMENT (SECOND) OF TORTS $§ 652 \mathrm{D} \mathrm{cmt.} \mathrm{h} \mathrm{(1977)).}$

114 The Boring decision has since been remanded by the 3rd Circuit Court of Appeals but only on grounds of trespass, which is outside the scope of this Note. (See Torsten Ove, Part of Suit against Google's Street View Reinstituted, PitT. Post GaZeTte, Jan. 29 2010, available at http://www.post-gazette.com/pg/10029/1032060100. stm? cmpid=localstate. $x \mathrm{ml}$.

115 Prosser, supra note 31, at 391-92.
} 


\section{No Right to Privacy Claim}

As discussed above, European lawmakers and American commentators have taken a different view of Street View then the traditional U.S. approach. ${ }^{116}$ These commentators have maintained that the U.S. framework of privacy in regards to Google Street View is ill conceived and the invasion of privacy torts should be expanded to encompass the traditional Google Street View plaintiff. For the reasons discussed below, this position should be rejected.

\section{A. The Problem with the Rationales Offered by Scholars}

One of the main arguments detractors of the current privacy framework aptly employ is that individual activities are stifled or chilled by Street View. They claim that Street View hinders one's freedom of expression and association on the public streets and tort law should be corrected to mitigate this error. ${ }^{117}$ However, this argument fails to countenance the fact that numerous other forms of video surveillance are omnipresent in American society that are tacitly accepted and do not seem to chill behavior. This surveillance is in fact more intrusive than Google's Street View images, since it may monitor individuals not just for a snippet in time, but over a period of time. ${ }^{118}$ For example, in the cities of London, England and Baltimore, Maryland blue light cameras have been installed throughout high crime areas. ${ }^{119}$ These systems not only serve as a means of emergency response for police; they are also equipped with video cameras which may monitor those citizens that use the blue-light system in real time as police are

\footnotetext{
116 See discussion supra pp. 1-2, 14-19.

117 See Kelley, supra note 6, at 225; Lavoie, supra note 3, at 605-06; Blackman, supra note 6, at 327, 347.

118 It is to be noted that the Georgia Law Review has also argued against such video surveillance based upon the chilling of behavior, even activity that is innocent in nature. This argument, however, is countered with the fact that these surveillance methods have been approved and accepted in our society as a legitimate aid to law enforcement. See Lavoie, supra note 3, at 595-96.

119 Justin Fenton, Baltimore Britain and Eyes of the Law, BALTIMORE SUN, Dec. 31, 2009, available at http://articles.baltimoresun.com/2009-12-31/news/bal-te.cameras31dec31_1 cameras-cctv-baltimore-sun-sentpolice.
} 
dispatched to the area. ${ }^{120}$ In fact, individuals that perpetrate crimes have been known to damage the blue light camera systems so that their activities may not be monitored by law enforcement. ${ }^{121}$ Moreover, in the United Kingdom there is a wide-ranging CCTV network in which government authorities may monitor individuals as they walk down the street or ride in public buses. ${ }^{122}$

From this argument flows the next assertion made by scholars, that individuals using the blue light system have consented to its use, while individuals caught on Google Street View have not consented to photographic imagery capture. This argument, however, runs counter to American principles of the 'sliding scale' of privacy interests and expectations. Just as individuals in an automobile or those that place their personal trash on the curbside have a lesser expectation of privacy, ${ }^{123}$ so too do individuals that walk freely about the street absent any enclosure or system to shield themselves from the public eye. Moreover, contrary to assertions, ${ }^{124}$ Google serves a legitimate public interest in the capturing of imagery on the street for its Street View program. Street View provides a noteworthy public service in allowing for the dissemination of information regarding locations

${ }^{120}$ Id.

${ }^{121}$ It could be maintained that a private corporation monitors the activities involved in Street View while the video surveillance program of blue light cameras is monitored by the government. However, Google has received government sanction for most of its monitoring activities. See Chu, supra note 2.

${ }^{122}$ Fenton, supra note 119. It is to be noted that suits have been initiated in the UK regarding the police's storage of a man's CCTV image for too long. (See Treacy, supra note 93). This litigation has not been resolved.

${ }^{123}$ See e.g., California v. Greenwood, 486 U.S. 35 (1988) and South Dakota v. Opperman, 428 U.S. 364, 367 (1976). It could be maintained that there are alternatives to using an automobile or trash collection, while one is obligated to use the public streets. As such, it is argued that due to the essential nature of the medium of public streets greater protections should be afforded to its users. This argument, however, fails to take account of the practical public policy served through denying privacy protection to conduct on the streets. Expanding privacy protections to individuals walking about the street creates a new level of government regulation and review of the activities of individuals that could often be embarrassing and invasive for the participants involved in subsequent litigation; far more so than the publication of an image among the vast ocean of images on Google Street View. See, e.g., discussion supra pp. 20-22; Boring, supra note 14, at 700 (discussing the increased attention the lawsuit against Google has brought in relation to the mere photographs in question). Moreover, practically administering such safeguards due to the sheer volume of individuals that use public streets, would prove quite untenable in nature and place a great strain on the resources of the courts.

${ }^{124}$ Lavoie, supra note 3, at 610-12. 
such as terrain, lighting, activities within walking distance, and parking possibilities. Even the ability to understand the world around oneself can be viewed as a public interest, allowing for the constitutionally protected free movement of peoples. As Google's Product Manager announced with the arrival of Street View, the program is a vehicle to "further enhance [users'] ability to understand the world through images by viewing and navigating within 360-degree scenes of street-level imagery.",125

Commentators' concerns regarding Street View's technological medium and control of individual information, while meritorious, also seem to have drawbacks. While magnification of Street View imagery is allowed, a record is still created, making the technology no different from an individual photograph one stores and subsequently reproduces in a magazine article. The centralization is greater and location of images is far easier than a traditional magazine, but the Street View searcher must still have a general idea of the intersection where the activity to be located occurred. For example, the smoker and government official discussed above can only be discerned if the Street View user is viewing Street View images of the particular intersection or sidewalk in which they were filmed. Otherwise, the searcher is no different than the general magazine subscriber flipping through the pages out of interest. There is the possibility that the image in question may happen to correspond with the searcher's directional search, but this is similar to if one were reading a magazine article of interest and the Gill photo appeared in the story.

One may maintain that the medium of the Internet allows for greater dissemination of information outside of an individual photograph, as well as allows for centralized storage of

\footnotetext{
${ }^{125}$ Posting of Stephen Chau to Google-Latlong.Blogspot.Com, http://googlelatlong.blogspot.com/2007/05/introducing-street-view.html(May 29, 2007, 10:11 EST) (last visited April 14, 2010).
} 
information, rather than mere 'snippets' in individual photographs. ${ }^{126}$ Yet the law should not be looking to protect behavior that is patently volunteered out in the open and disseminated in a medium integrated into our daily lives. Just as individuals are prudent regarding the information they disclose to individuals, they should similarly be prudent in their displays in public. While this may seem like an unnecessary sacrifice for individuals, and a hindrance of their freedom of expression, the law currently assumes prudence and reasonableness in one's actions. ${ }^{127}$ It could be maintained that in reality reasonableness is not exhibited, however, reasonableness should be re-emphasized and inculcated in individuals. Creating an invasion of privacy remedy for Google Street View allows reasonableness to languish due to excessive concerns over safeguarding minimal privacy interests and rewards non-diligent conduct. This cycle would be the equivalent of surrendering in the battle over reasonableness and would make the law's assumption a true fallacy rather than a debatable issue. As one commentator eloquently stated,

The Internet creates irrational behavior in otherwise rational individuals. For example, most people would never dream of walking up to a stranger and opening up a photo album of their families and sharing the details of their life with them. But the Internet contains countless examples of exactly that scenario. Unfortunately, Internet users have shown a willingness to share much more than photos. Through social networking sites, users share intimate life details with a mix of friends and strangers. Privacy cannot be regained once lost. It becomes critically important that one of the earliest life lessons, "Don't talk to strangers," transcend our actions on the Internet. No government or website provider can take the place of individual user privacy decisions on the Internet. Government and website providers can insure that the privacy tools available are effective, but the ultimate guardian of privacy is the individual. ${ }^{128}$

\footnotetext{
${ }^{126}$ See Michael Zimmer, Privacy on Planet Google: Using the Theory of "Contextual Integrity" to Clarify the Privacy Threats of Google's Quest for the Perfect Search Engine, 3 J. Bus. \& TECH. L. 109 (2008).

${ }^{127}$ Robert C. Post, The Social Foundations of Privacy: Community and Self in the Common Law Tort, 77 CAL. L. REV. 957, 963 (1989) (discussing that the reasonable person protects and reflects deference and demeanor).

${ }^{128}$ Brian Kane \& Brett T. Delange, A Tale of Two Internets: Web 2.0, Slices, Dices, and is Privacy Resistant, 45 IDAHO L. REV. 317, 345 (2009) (citations omitted).
} 
Similarly, contrary to the apt assertions of scholars, ${ }^{129}$ the information gleaned by Google does allow for mechanisms for one to control the information collected about him or herself. Google has gone to great expense to attempt to automatically blur the faces and license plates captured through its technology and allow for a procedure to have information blurred should the software fail. Moreover, Google has updated and improved their removal process to allow for greater efficiency and ease of removal of objectionable images in their program. While one is not notified when an image of himself is placed on Street View, practice of the reasonable behavior outlined above would mitigate such issues. ${ }^{130}$

\section{B. The Problem with Expansion of the Privacy Tort}

The rationales discussed above have led commentators to call for an expansion of the current torts of invasion of privacy to encompass Street View plaintiffs. ${ }^{131}$ These commentators cite Justice Carter's dissent in the Gill case as creating the basis for a new privacy tort. ${ }^{132}$ Wideranging measures have also been called for, such as obliterating the distinction between public and private activity, ${ }^{133}$ implanting a test creating liability based upon the form of dissemination

${ }^{129}$ Lavoie, supra note 3, at 606-08.

${ }^{130}$ It could be argued that this failure of notification by Google makes other privacy safeguards irrelevant in a practical sense. Yet practical implementation of a notification system for every person captured in street images would prove highly costly. Moreover, given current national registries around the world, the system is tenuous as a proposition. It is also important to note that a user of Street View could view areas he frequently visits in order to determine whether the database includes his image. While this may be seen as an unnecessary inconvenience to individuals, again practice of reasonableness in public displays would mitigate such an issue.

131 See Kelley, supra note 6, at 224-30; Blackman, supra note 6, at 341-92.

132 As the Santa Clara Law Review stated, "Unbeknownst to him, Justice Carter outlined in his dissent in Gill factors that can define torts committed with future technologies: (1) people expect to be private when keeping to themselves, (2) intruding upon this solitude is offensive, (3) the intrusion is especially offensive when the image is reproduced, and (4) there is no news value in incidental occurrences of average people." Blackman, supra note 6, at $324-25$.

${ }^{133}$ Kelley, supra note 6, at 226-27; Blackman, supra note 6, at 354-61. Often this is based on the idea of one consenting to activity in public as a "fiction." In other words that one cannot consent, much less knowingly participate, in activities in society. See Kelley, supra note 6, at 213-14. This argument fails because, while an individual cannot know which activities they will encounter while in public, they certainly can control the activities they voluntarily undertake in public such as: smoking, sunbathing in little clothing, building additions to their home, or affectionately walking about with another woman to whom he is not married. The images are merely frozen in time; if seen by a casual passerby one would think it absurd to challenge such a person testifying in Court to such 
(medium based), ${ }^{134}$ changing the analysis of a reasonable person and what is highly offensive, ${ }^{135}$ as well as altering the definitions of 'newsworthiness' and 'legitimate public benefit.',136

These proposals, however, have numerous drawbacks. The obliteration of the public/private divide in activity runs counter to well-established principles of American law. While public activity has been given the shield of privacy in a Fourth Amendment context, this has focused on searches and seizures depriving one of their liberty interests. ${ }^{137}$ In contrast, the activity embraced in Street View constitutes no such seizure of the plaintiff but is rather the republication of imagery on the Internet. The Supreme Court and numerous other courts, including the Gill court, have explicitly allowed this activity. ${ }^{138}$ It could be maintained that Street View is capturing inherently private activities on the street, such as the smoker discussed above, ${ }^{139}$ however, these activities took place out in the open view of a mere passerby where an individual's privacy is inherently limited. ${ }^{140}$ How private could the activity be? The individuals took no steps to mitigate their exposure to the casual tourist passerby taking photographs, so why should Google be limited in their ability to record such activity?

The answer to the above questions proposed by commentators is the medium that Google employs. These commentators assert that a new privacy tort should allow for liability based upon the wide dissemination that the Internet provides, creating mass distribution of Street View's imagery and too large a scope for current norms. Yet expansion of the privacy torts to

events. Moreover, the law assumes that one is reasonable in public but the Internet has decreased this assumption of reasonableness. See discussion supra pp. 8, 25-26. Embracing the public as a fiction argument lowers the accountability of individuals for their actions, rewards unreasonable public behavior, and lowers the personal reasonableness that should be re-inculcated in individuals. See Kane, supra note 128, at 345.

134 Blackman, supra note 6, at 365-73.

135 Id. at 363-65; Kelley, supra note 6, at 227-28.

136 Blackman, supra note 6, at 373-89.

${ }^{137}$ Lavoie, supra note 3, at 594-96.

138 See discussion supra pp. 10-14.

139 See discussion supra p. 1.

${ }^{140}$ See Prosser, supra note 31, at 391-92; Opperman, supra note 123, at 367; Greenwood, supra note 123, at 40-41. 
encompass this criterion ignores the analogous use of imagery in the Gill case in which the photograph of the couple was widely disseminated to magazine subscribers. ${ }^{141}$ The images challenged in Street View capture the same seemingly private moments that the couple's photograph captured in Gill. While this position is tenuous in light of the argument against wide distribution of a frozen image of a moment in time ${ }^{142}$ developed in Justice Carter's eloquent dissent, even under his privacy framework Google Street View would survive due to the explicit public service its images serve. Unlike the image of the Gill couple, which could be argued to merely serve the function of individual viewership for prurient or self-interest, Street View images consistently allow users to witness terrain and areas for safety, house hunting, ${ }^{143}$ travel, and even crime solving. ${ }^{144}$ While the display or action itself might not have a legitimate public interest, the program and its general photographing does.

Scholars' calls for change of the newsworthiness/public purpose requirement of the privacy torts while meritorious also have drawbacks. As is acknowledged in the literature suggesting such a change, newsworthiness and the ability to print materials in the press involves a core First Amendment right, which while not absolute, requires limitations on the right to be circumscribed. ${ }^{145}$ As such, tests proposed to limit this authority are subject to scrutiny and Constitutional limitations. Moreover, as also acknowledged within the literature, this area of law

\footnotetext{
${ }^{141}$ Commentators' calls to base invasions of privacy upon the medium or forum of image capture, such as the street, create a classification system at the risk of destroying uniformity. See Blackman, supra note 6, at 365-73. The individual that is photographed by a passerby on the street (an area, again, that is historically granted minimal privacy protections) while satisfying the public/private obliteration does not satisfy the dissemination prong even though the image could be reproduced in magazines throughout the nation, while the image of an individual disseminated over the Internet would be able to challenge such an action.

142 See discussion supra pp. 11-12.

${ }^{143}$ UK analysts have recommended a Google Street View search when buying a home as a means to look at roads from the ground level in and around prospective property. See Alison Jones, Location, location etc really is a priority; It's not just a home you are buying into, it's a neighbourhood. Alison Jones investigates ways of finding about the area you are considering moving too. BIRMINGHAM POST, February 18, 2010, at 28.

${ }^{144}$ Kirtley, supra note 87, at 65.

${ }^{145}$ Kelley, supra note 6, at 228; Blackman, supra note 6, at 373-75.
} 
is based on concepts of Federalism and state-by-state analysis. ${ }^{146}$ Imposition of a federal standard runs counter to this historical right.

Even if these barriers were to be overcome, the tests proposed are quite vague in application. One proposal is to more critically question the news value of the proposed image outside of the traditional deference to the image producer. ${ }^{147}$ This proposal ignores the subjective nature of such an analysis, with individuals often having different conceptions of newsworthiness. ${ }^{148}$ As such, repression of imagery could become the norm, running counter to First Amendment principles. Moreover, the proposals designed to further define newsworthiness are also subjective in nature, which would create the necessity of case-by-case analysis, untenable in a proposed federal framework. ${ }^{149}$

\section{Conclusion- Allow Technological Progress to Continue}

While Google's Street View program has raised numerous concerns among European lawmakers and American commentators, an analysis of the rationales and calls for expanded privacy torts by these commentators has yielded ambiguity. Google's Street View program serves a newsworthy public service in crime solving, terrain investigation, as well as investigation surrounding travel, safety, and daily activities. Countered against this noteworthy public service are the privacy interests of those that are inadvertently captured on camera. These

\footnotetext{
146 Blackman, supra note 6, at 389-90.

${ }^{147}$ Id. at 377-79; Kelley, supra note 6, at 228.

148 See, e.g., Hearst, supra note 34. These similar subjective pitfalls also hinder calls for change in the analysis of the highly offensive requirements and reasonable person requirements to one respectively based upon a merely offensive requirement and individual preconceptions rather than community norms. See Kelley, supra note 6, at 215-18, 228; Blackman, supra note 6, at 364-65. This, however, would also bring greater issues of subjectivity into the equation, which the term 'highly offensive,' serves to mitigate. Criticisms of the current assessment of the reasonable person under the privacy torts, which is based upon the norms of the intruding media, are also in error. See Kelley, supra note 6, at 215-18, 228. While the reasonable person is to represent someone who fully obeys all the relevant civility rules and is idealized in society, this person is an "abstraction." Post, supra note 127, at 961. Failure to be guided by intruding media norms cannot illuminate the relevant civility rules if viewed outside of community norms.

149 These proposals include: societal value, intrusion into private matters, and public notoriety. See Blackman, supra note 6, at 379-89.
} 
individuals, fully out in the open without taking any mitigating steps to reduce identification, have been found behaving unreasonably by the casual passerby. While the plight of the individuals in these cases is certainly to be felt, expanding the torts of invasion of privacy to encompass such activities removes accountability and prudence that is presumed by the law to be present in individuals in their daily activities. Just as the law does not shield those ignorant of its precepts, it should not shield those engaging in certain behavior within the public eye.

Yet Google has even gone a step further in protecting these individuals that have minimal privacy protections due to their public activities. Putting in place protections for an individual that allows his duly elected representatives to place blue light cameras on the streets of his city and video cameras on his public bus. Creating a practical paradox for all to see. They have implemented an image mitigation program to blur faces and license plates, allowed for a userfriendly mechanism to remove images from the Street View program, and in Europe, have even given advance warning of the locations it intends to photograph. While in the U.S. an individual does not receive advance notice of photographing and must know that they have been photographed on Street View, the subsequent image search, given the current state of technology, plethora of Street View images, and national registries, is not a heavy price to bear for one that perpetuates unreasonable behavior. "Users must become more responsible."150

Expanding the privacy torts to encompass the Street View plaintiff thwarts the technological progress that has streamlined and centralized life. Google's Street View Program has created a greater sense of ease than could have even been imagined twenty-five years ago. While the plight of the smoker having to explain his addiction to his family and friends will create possible tension in his home, and while Street View has penetrated his 'seeming bubble of

\footnotetext{
${ }^{150}$ Kane, supra note 128 , at 345 . It is to be noted that given the general trend in Europe and the potentiality of future U.S. litigation, Google Street View may eventually initiate warnings in the United States of future photographing locations out of ease, cost, and uniformity. The author would view this as a reasonable alternative.
} 
solitude,' it is not enough to thwart the wheels of technological progress and overhaul our nation's system of privacy torts. As the British Information Commission stated, "the digital clock should not be turned back."151

${ }^{151}$ Press Release, supra note 91. 